\section{Commentary: New lungs may be right around the corner}

\author{
Samantha E. Halpern, BA, ${ }^{\mathrm{a}}$ and \\ Matthew G. Hartwig, MD, MHS
}

Lung transplantation (LTx) has long faced organ shortage, necessitating equitable allocation of allografts balanced with projected transplant benefit. Within this calculus, medical urgency and geographic feasibility must be considered. In 2005, the Lung Allocation Score revolutionized candidate prioritization, decreasing waitlist mortality and increasing transplantation of critically ill patients. ${ }^{1}$ However, allocation of donor lungs first within a donation service area (DSA) restricted high Lung Allocation Score candidates' access to available lungs. Lung allocation policy was emergently revised in November 2017, replacing DSA with a 250-nautical mile radius around the donor hospital as the first unit of lung allocation. ${ }^{2}$ This facilitates broader sharing of donor lungs to urgent candidates, but replaces a residual cliff in allocation at arbitrary DSA borders, with one at $250 \mathrm{nms}$. Unsurprisingly, early reports demonstrated an increase in the distance donor lungs travel to reach recipients and a decline in local (within DSA) LTx. ${ }^{3,4}$

These data raise the question of whether post-transplant outcomes are affected by use of local versus distant donor lungs, a question addressed by Gerull and colleagues ${ }^{5}$ in this issue of the Journal. They conducted a retrospective cohort study of 722 LTx performed at their institution, including $392(54 \%)$ local and $330(46 \%)$ distant transplants. The study revealed no difference in 1-year mortality or chronic lung allograft dysfunction between groups; however, use of distant donor lungs was associated with longer ischemic times (median 346 vs 319 minutes), nighttime transplantation ( $39 \%$ vs $15 \%)$, and higher estimated costs (median $\$ 229,871$ vs $\$ 183,542$ ). This study sheds some light on the

From the ${ }^{\mathrm{a}}$ School of Medicine, Duke University, Durham, NC; and ${ }^{\mathrm{b}}$ Division of Cardiovascular and Thoracic Surgery, Department of Surgery, Duke University Medical Center, Durham, NC.

Disclosures: The authors reported no conflicts of interest.

The Journal policy requires editors and reviewers to disclose conflicts of interest and to decline handling or reviewing manuscripts for which they may have a conflict of interest. The editors and reviewers of this article have no conflicts of interest.

Received for publication Aug 14, 2020; revisions received Aug 14, 2020; accepted for publication Aug 17, 2020; available ahead of print Aug 20, 2020.

Address for reprints: Matthew G. Hartwig, MD, MHS, Duke University Medical Center, Box 3863, Durham, NC 27710 (E-mail: matthew.hartwig@ duke.edu).

J Thorac Cardiovasc Surg 2021;162:1294-5

$0022-5223 / \$ 36.00$

Copyright $($ C 2020 by The American Association for Thoracic Surgery

https://doi.org/10.1016/j.jtcvs.2020.08.049

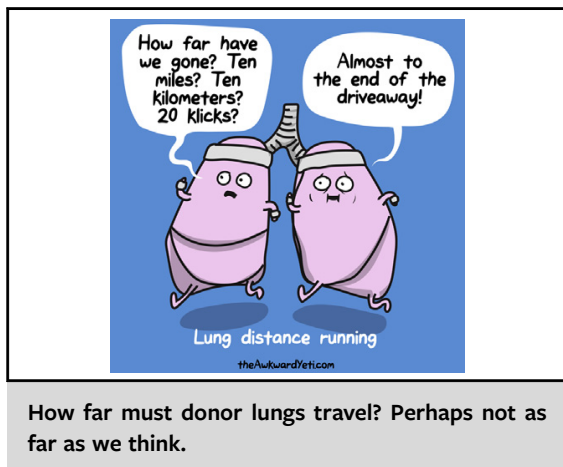

CENTRAL MESSAGE

Use of distant donor lungs is safe, albeit more costly and logistically cumbersome. Efforts to increase lung availability may improve access to transplantation and reduce need for distant

procurement.

impact of moving beyond DSA for first allocation. However, beyond-DSA donors are not necessarily "distant" donors.

The authors conclude that, while safe, broader lung sharing may increase costs and complicate LTx logistics as procurement teams travel farther and coordinate with nonlocal organ procurement organizations (OPOs) to acquire donor lungs. They suggest several possible solutions, including the use of collaborative OPO-based procurement teams, centralized donor management facilities, and, when possible, daytime transplantation to reduce resource use and organ transport times to streamline LTx in this new era.

Notably absent, however, is discussion of the potential to increase lung availability, decreasing need for distant procurements and minimizing the aforementioned issues. A growing body of literature suggests tremendous unrealized donor potential in the United States. In a national study, Klassen and colleagues ${ }^{6}$ estimated that potential donors represent $1.4 \%$ to $1.5 \%$ of annual deaths; of those, actual donors represent only $16 \%$ to $21 \%{ }^{6}$ Goldberg and colleagues ${ }^{7}$ likewise found that inpatient deaths leading to donation varied from $20 \%$ to $57 \%$ among OPOs, suggesting that maximizing OPO performance could result in thousands of additional transplants annually. While revised OPO performance monitoring may begin to address these issues, ${ }^{8}$ OPOs and transplant centers must collaborate to realize this untapped donor potential. 
In summary, Gerull and colleagues ${ }^{5}$ offer compelling evidence to motivate ongoing scrutiny of lung allocation policy to optimize transplant efficiency, without sacrificing post-transplant outcomes. Although distant LTx may be the current reality, ultimately, new lungs may be right around the corner.

\section{References}

1. Egan TM, Edwards LB. Effect of the lung allocation score on lung transplantation in the United States. J Heart Lung Transplant. 2016;35:433-9.

2. OPTN/UNOS Executive Committee. Broader Sharing of Adult Donor Lungs. Available at: https://optn.transplant.hrsa.gov/media/2314/broader_sharing lungs_20171124.pdf.

3. Lehman RR, Carrico B. Monitoring of the Lung Allocation Change, 1 Year Report. Available at: https://optn.transplant.hrsa.gov/media/2815/20190116_thoracic _committee_report_lung.pdf.
4. Puri V, Hachem RR, Frye CC, Harrison MS, Semenkovich TR, Lynch JP, et al. Unintended consequences of changes to lung allocation policy. Am J Transplant. 2018;19:2164-7.

5. Gerull WD, Yang Z, Kreisel D, Nava R, Meyers BF, Patterson GA, et al. Loca versus distant lung donor procurement does not impact short-term clinical outcomes. J Thorac Cardiovasc Surg. 2021;162:1284-93.e4.

6. Klassen DK, Edwards LB, Stewart DE, Glazier AK, Orlowski JP, Berg CL. The OPTN deceased donor potential study: implications for policy and practice. Am J Transplant. 2016;16:1707-14.

7. Goldberg D, Kallan MJ, Fu L, Ciccarone M, Ramirez J, Rosenberg P, et al Changing metrics of Organ Procurement Organization performance in order to increase organ donation rates in the United States. Am J Transplant. 2017;17: 3183-92.

8. Centers for Medicare \& Medicaid Services, United States Department of Health and Human Services, Medicare and Medicaid Programs. Organ Procurement Organizations conditions for coverage: revisions to the outcome measure requirements for Organ Procurement Organization. Fed Regist. 2019; 84:70628-710.
See Article page 1284.

\section{Commentary: Long-distance relationships work well in lung transplantation}

\author{
Konrad Hoetzenecker, MD, PhD
}

A considerable number of long-distance donor organs are still rejected based on a fear that post-transplant outcomes might be impaired by the prolonged cold ischemic time (CIT). In this issue of the Journal, Gerull and colleagues ${ }^{1}$ analyzed a cohort of patients transplanted at the Washington University and compared recipients of local donors with recipients receiving a distant donor organ. Early- and longterm outcomes of both groups were identical, despite the fact that recipients with distant donors had a greater lung allocation score and were more likely to be intubated or

\footnotetext{
From the Department of Thoracic Surgery, Medical University of Vienna, Vienna, Austria.

Disclosures: The author reported no conflicts of interest.

The Journal policy requires editors and reviewers to disclose conflicts of interest and to decline handling or reviewing manuscripts for which they may have a conflict of interest. The editors and reviewers of this article have no conflicts of interest.

Received for publication Aug 11, 2020; revisions received Aug 11, 2020; accepted for publication Aug 12, 2020; available ahead of print Aug 15, 2020

Address for reprints: Konrad Hoetzenecker, MD, PhD, Division of Thoracic Surgery,

Medical University of Vienna, Waehringer Guertel 18-20, 1090 Vienna, Austria

(E-mail: konrad.hoetzenecker@meduniwien.ac.at).

J Thorac Cardiovasc Surg 2021;162:1295-6

$0022-5223 / \$ 36.00$

Copyright (c) 2020 by The American Association for Thoracic Surgery

https://doi.org/10.1016/j.jtcvs.2020.08.030
}

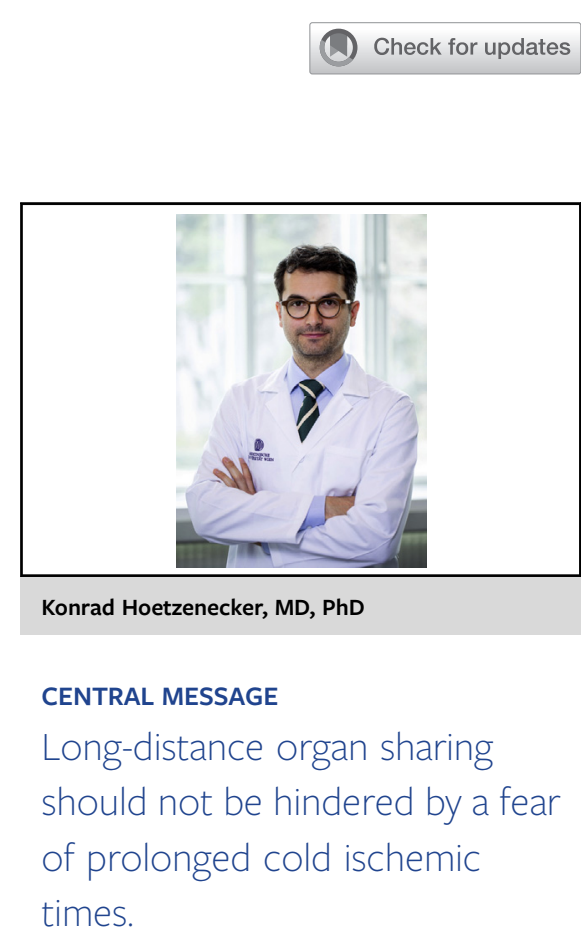

on extracorporeal life support before the transplant. Of note, $63 \%$ of the distant organs had an ischemic time of $>300$ minutes as compared with only $12 \%$ in the local donor group.

These findings are in line with other publications, which question the importance of CIT for early organ function. Traditionally, 6 hours is considered the acceptable CIT threshold for a donor lung. ${ }^{2}$ However, Hayes and colleagues ${ }^{3}$ found, in a diligent analysis of United Network 